\title{
THE NATIONAL INSTITUTE OF MEDICAL SCIENCES AND NUTRITION SALVADOR ZUBIRÁN: A BRIEF JOURNEY THROUGH ITS HISTORY
}

\author{
DaVID KeRShenobich-STALNIKOWITZ* \\ General Director, Instituto Nacional de Ciencias Médicas y Nutrición Salvador Zubirán, Mexico City, Mexico
}

The National Institute of Medical Sciences and Nutrition Salvador Zubirán (INCMNSZ) is an institution of reference in health that provides specialized medical attention in adults, training of human resources, and research, with an integral approach and excellency for the benefit of human beings and their environment (Table 1).

On December 1, 1944, the founding charter of the Hospital for Nutrition Diseases (Hospital de Enfermedades de la Nutrición, HEN) was published and signed by then Mexican President Manuel Ávila Camacho and the Minister of Health Dr. Gustavo Baz Prada. On January 6, 1945, Dr. Salvador Zubirán was appointed as its first Director General. On October 12, 1946, the hospital, located in Mexico City, was formally inaugurated, committed to three basic activities: health care, scientific research, and education. The new hospital began with two divisions, nutrition and medicine; three departments, endocrinology, gastroenterology, and hematology; and three interconsultant services, dermatology, endoscopy, and urology. It had five sections, teaching (lecture hall and library), nursing, outpatient services, laboratory, and radiology services, two hospitalization wards. General services included administration, admissions and social work, clinical archives, kitchen, dining hall and nutrition services office, pharmacy, maintenance and storage, garment, and laundry service. A board of trustees was appointed the same year.

The emblem of the hospital depicts a laboratory flask with a snake to highlight medical research; corn and wheat symbolizing nutrition of the people; the name of the hospital, and a Latin text, "Nutritionis scientia populi salus," meaning that "The science of nutrition is the health of the people" (Fig. 1). Why was the hospital given the name of Nutritional Diseases? Dr. Salvador Zubirán explains: "In addition to my particular inclination to care for the nutrition of the people, there was at that time in the world a very strong movement of renewal of scientists to study the problems related with human nutrition. Vitamins were being discovered. Many of those who received the Nobel Prize were investigating nutrition processes... We decided to formally name our new hospital the Hospital of Nutritional Diseases since at the time it was considered essential to provide care to the population suffering from malnutrition, and the sequelae caused by it."

In 1955, the hospital changed its name to National Institute of Nutrition (INN); three years later, in 1958, the Medical Association of the National Institute of
*Corresponding author:

David Kershenobich-Stalnikowitz

E-mail: kesdhipa@yahoo.com
Received for publication: 05-07-2021

Approved for publication: 22-07-2021

DOI: $10.24875 / R I C .21000387$

0034-8376 / (c) 2021 Revista de Investigación Clínica. Published by Permanyer. This is an open access article under the CC BY-NC-ND license (http://creativecommons.org/licenses/by-nc-nd/4.0/). 
Figure 1. Institutional identity. The emblem: the laboratory flask with a snake symbolizes research in the field of medicine; the wheat and corn leaves symbolize the nutrition of our people.
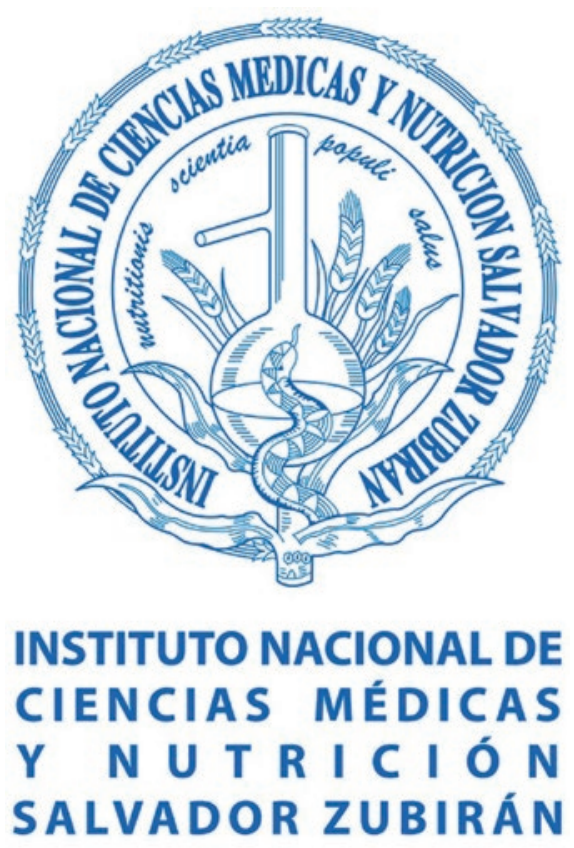

Nutrition (AMINN) was founded. Relocation of the Institute to its new premises on the south of Mexico City (Tlalpan) was concluded in 1969. In 1981, the name of Salvador Zubirán was appended to the name of the Institute, and, in 2000, the law of the National Institutes of Health published in the Official Daily Gazette of Mexico stated that the Institute's name be changed to National Institute of Medical Sciences and Nutrition Salvador Zubirán (INCMNSZ).

The itinerary followed by the institute is a testimony of its founder's vision. What has happened to this date, is a history of 75 years of achievements that resembles a Rubik's cube, the famous magic cube, which allows to understand a third dimension by solving a structural problem moving the parts independently without the total collapse of the mechanism. Currently, the governance of the institute is being conducted by the director general and nine directors of areas (medicine, surgery, research, teaching, nutrition, general administration, planning, institutional development, and institutional and social communication). Steadily, the number of departments and services has been added over the years. Herein, I select a sample than can give us a representative frame of this course of action. In 1947, the Division of Surgery and the Departments of Pathology, MicrobiologyParasitology and Cardiology were added. In 1953, the Thyroid Clinic. In 1957, the Biochemistry Laboratory. In 1958, the Diabetes Clinic and the Nursing School. In 1959, the Department of Nephrology and Mineral Metabolism. In 1960, the Department of Experimental Surgery and Transplant Unit. In 1965, the Departments of Nuclear Medicine, Clinical Physiology and Reproductive Biology. In 1966, the Department of Immunology and Rheumatology. In 1967, the Department of Genetics. In 1968, the Division of Research was inaugurated. Between 1971 and 1972, the Anesthesia Service, Special Care and Post-Anesthesia Unit and the Pain Clinic. In 1977-1978, the Urology Department, the Department of Informatics and Computer Science. In 1979, the Infectious Diseases Department, and in 1982, a food technology pilot plant. In 1983, the Gastrointestinal Endoscopy Department. In 1987, the Department of Health Education and also the Unit of Geriatrics. In 1989, the Oncology Department. In 1991, a Comprehensive Training Center for Community Developers (CECIPROC) in Oaxaca, and the Department of Dermatology. Furthermore, a new laboratory animal facility was opened. In 1996, the Department of Neurology and Psychiatry. In 2005, the Medical Skills Development 
Simulator Center (CEDDEM). In 2013, a Center for Comprehensive Care of Diabetic Patients (CAIPADI). In 2015, the Institutional and Social Communications Department. As $40.6 \%$ of the patients attending the institute present three or more pathologic entities, internal medicine and surgical attention mostly are highly specialized and complex. For that purpose, at least 34 specialized clinics provide an integral model of care.

In 1974, the auditorium, the new library, and the teaching classrooms were inaugurated. In 1993, the Don Quijote fountain was installed in the premises. In 1994, the new medical residence Dr. Manuel Campuzano Fernández entered into operation. In 1995, the tower and the fourth floor of hospitalization were built; on that same year, the central sampling unit was inaugurated. In 2005, the name of Dr. Donato Alarcón Segovia was appended to the outpatient unit. In 2012, a new outpatient unit, "Dr. Fernando Gabilondo", was inaugurated. In 2014, a building was put into operation that houses the Radiotherapy and Chemotherapy Unit, the Research Support Network, RAI, conformed by a consortium of the Institute with the National University of Mexico (UNAM), the National Institutes of Cardiology, Cancer, and Genomic Medicine. In 2015, the Continuous Institutional Care and Emergencies Unit was renovated. In 2016, a Digital Consultation Area in the Library is put into operation. In 2017, a Proton Emission Tomography equipment started functioning in the Department of Nuclear Medicine. At present, a new molecular pathology facility and a new hospitalization tower are being built.

In 1948-1949, the first issue of the Revista de Investigación Clínica, RIC (Journal of Clinical Research) was published, and the first master's and doctoral courses in medical sciences were established in collaboration with the National Autonomous University of Mexico (UNAM). In 1959, the institute was designated as Center for Education and Training in Nutrition. In 1971, the World Health Organization (WHO) chose the Department of Reproductive Biology as an international Center for Clinical Research and Training in Human Reproduction. In 1983, the institute was selected as a reference center for treatment and research of HIV/AIDS. In 1984, the institute was appointed as Coordinator of the National Reference Center for Congenital Malformations. In 1987, the Department of Health Education was created. In
2008, the WHO enabled the Gastroenterology Department as an advanced training center. In 2009, the institute became part of the Flu Pandemic Readiness and Response Plan for H1N1 influenza virus. In 2012, the National Laboratory of Maximum Safety for the Study of Tuberculosis and Emerging Diseases (BSL3) and the Laboratory for Research on Viral Diseases (BSL2) were inaugurated. In 2013, a National Strategy for the Prevention of Overweight, Obesity, and Diabetes was launched, the Center for Comprehensive Care of Diabetic Patients (CAIPaDi) was created, and the first issue of the Revista Mexicana de Enfermería was published. In 2014, a visiting researcher program was started mainly for postgraduate fellows. Two research chairs were designated at the institute for foreign investigators. In 2017, the Research Unit on Metabolic Diseases, in association with the Technological Institute of Monterrey, was launched. Since March 2020, the institute actively participates in the care and research of patients with COVID-19, manifested in 87 publications, 61 of them in foreign journals.

All these actions do not occur by chance; they are related to scientific and clinical advances that modernized the biomedical and clinical fields, and to the relentless pursuit of the institute to incorporate higher quality medicine in the benefit of patients. The institute is committed to maintaining expertise based on attributes of professionalism at all levels, with the purpose of identifying aspiring leaders with innate talent that could foster new knowledge, and at the same time updating the institution in the different fields that shape global medicine. It is estimated that the doubling time of medical knowledge in 1950 was 50 years; in 1980, 7 years; and in 2010, it was 3.5 years. In 2020, it was projected to be 0.2 years, only 73 days.

Research at the institute is focused on elucidating the mechanisms involved in the pathophysiology of disease. It is characterized by newness and originality. It is a history of visionary ideas that have spread through areas such as nutrition, reproductive medicine, degenerative diseases, host-pathogen interactions, specialized surgery, displaying translational basic research, and health management. Through the years, the institute has contributed with investigations that have transcended and helped to advance medicine in general. Some examples include the first Nutritional 
Surveys from Community Studies that paved the way to the National Surveys of Health and Nutrition organized by the Federal Government. The identification of hereditary hemoglobinopathies. The study of the metabolic adaptations in malnutrition and obesity; the molecular mechanisms of nitrogen homeostasis. The study of pituitary and steroid hormones, and their biochemistry. The biology of human reproduction and the regulatory mechanisms of fertility in humans; contraceptive research and development. The unsuspected regulatory role of autoantibodies that can enter live cells and penetrate their nucleus. The pathophysiologic mechanisms of systemic lupus erythematosus; the demonstration of NETosis in inflammatory processes. The identification of T-CD4 as the primary affected cell in HIV. The role of human milk in infant nutrition and health. The epidemiology of rotavirus, development and implementation studies of rotavirus vaccine. A program to study the clinical and molecular epidemiology of tuberculosis and drug resistance. The studies on medical and surgical management of portal hypertension. The pathophysiology of liver fibrosis and the demonstration that collagen deposition in the liver is a reversible phenomenon. The study and repair techniques of biliary tract iatrogenic lesions. The pathophysiology of salt retention in kidney and hypertension; the role of aldosterone in acute ischemic injury. The scientific approach to diabetes mellitus and hyperlipidemia management that have shifted healthcare paradigms. The role of the vagal nerve in inflammatory processes. The performance of a bilateral upper limb transplant. The studies on microbiota and functional food. A new invasive ventilator, SZ20, patented by the bioengineering department in 2020. These investigations, among many others, have contributed with original ideas. Since 2016, a Unit of Intellectual Property initiated its activities. Overall, these examples are part of the research pillar which, together with the pillars of high standard medical care and education, provide the
Table 1. Major objectives of the National Institute of Medical Sciences and Nutrition Salvador Zubirán

- Provide comprehensive and specialized medical care with high quality and safety to the adult population, through a model that can be replicated

- Contribute to the development of actions to improve the nutrition of the population

- Extend the participation and impact of the institute's own activities at the national and international levels

- Train human resources at the highest scientific and technical level, with institutional value

- Advise the public, social, and private sectors in the areas of our competence

- Strengthen the institute's participation in continuing education for health professionals and in health education for the population

- Develop research, technological innovation, and medical programs that contribute to knowledge and social well-being

- Encourage the generation of institutional intellectual property

- Promote new models of communication and linkage taking advantage of trends and media accessible to the outside and inside

- Implement an innovative model of organization and administration

strong structure and credibility that have made the INCMNSZ a national and international reference center. The major objectives of the institute are shown in table 1.

Along these 75 years, the institute has had the support, among others, from the Mexican Government, national and international agencies and funds, universities, civil societies, donors, and the institutional board. These sponsorships have played a significant role in fostering research and training of human resources. 